\title{
AN INVESTIGATION INTO THE DETERMINATION OF CORTICOSTEROIDS IN URINE \\ I. THE DETERMINATION OF CORTICOSTERONE-LIKE SUBSTANCES
}

BY

\author{
S. L. TOMPSETT \\ From the Biochemical Laboratory, Northern General Hospital, Edinburgh, and the Department of Clinical \\ Chemistry, University of Edinburgh
}

(RECEIVED FOR PUBLICATION JUNE 27, 1952)

In the present investigation it has been found that the ability of deoxycorticosterone and corticosterone to produce the theoretical amount of formaldehyde when treated with periodic acid is unimpaired by previous treatment with hot dilute mineral acids. The ability of cortisone to react with periodic acid to produce formaldehyde is reduced to negligible proportions by such treatment. As a result a method is described in this paper for the determination in urine of metabolites closely related to corticosterone and deoxycorticosterone. Metabolites related to cortisone and similar 17-hydroxycorticoids are not included. A modified form of the periodic acid reaction has been employed.

\section{The Liberation of Formaldehyde from Deoxycortico- sterone Acetate and Cortisone Acetate}

Deoxycorticosterone and cortisone acetates do not react with periodic acid to produce formaldehyde under the conditions used by Daughaday, Jaffe, and Williams (1948), since the terminal $-\mathrm{CH}_{2} \mathrm{OH}$ group is esterified with acetic acid. In view of the suggested lability of these substances to hot mineral acid, it was decided to investigate the possibility that the two reactions, (1) hydrolysis with a mineral acid at $100^{\circ} \mathrm{C}$. and (2) the periodic reaction. could be run simultaneously.

The steroid acetate. $1 \mathrm{mg}$. dissolved in $1 \mathrm{ml}$. of absolute alcohol, was distilled with dilute sulphuric acid and periodic acid and the quantity of formaldehyde liberated determined in an aliquot of the distillate. The details are exactly as those described below. Formaldehyde was determined from a curve obtained by subjecting known amounts of formaldehyde to the same treatment.

From the results shown in Table I it will be seen that the theoretical amount of formaldehyde could be obtained from both steroid acetates by the technique employed.

The effect of previous treatment with hot dilute mineral acid and hot alkali was then examined.
TABLE I

RECOVERY OF FORMALDEHYDE AFTER REACTION OF DEOXYCORTICOSTERONE AND CORTISONE ACETATES WITH PERIODIC ACID

\begin{tabular}{|c|c|c|}
\hline \multicolumn{2}{|l|}{ Deoxycorticosterone Acetate } & \multirow[b]{2}{*}{$\begin{array}{c}1 \mathrm{mg} . \\
81 \mathrm{mg} \\
6 \\
78-84 \mathrm{mg}\end{array}$} \\
\hline $\begin{array}{l}\text { Quantity of acetate used } \\
\text { Quantity of formaldehyde expected } \\
\text { Number of determinations } \\
\text { Quantity of formaldehyde determined }\end{array}$ & $\begin{array}{l}\cdots \\
\cdots \\
\cdots\end{array}$ & \\
\hline Percentage of the theoretica! & $\cdots$ & $96-104$ \\
\hline \multicolumn{3}{|l|}{ Cortisone Acetate } \\
\hline $\begin{array}{l}\text { Quantity of acetate used } \\
\text { Quantity of formaldehyde expected } \\
\text { Number of determinations } \\
\text { Quantity of formaldehyde determined }\end{array}$ & $\begin{array}{l}\cdots \\
\cdots \\
\cdots\end{array}$ & $\begin{array}{c}1 \mathrm{mg} \\
74 \mu \mathrm{g} \\
6 \\
70-78 \mu \mathrm{g}\end{array}$ \\
\hline Percentage of the theoretical & $\ldots$ & $94-105$ \\
\hline
\end{tabular}

Steroid acetate, $1 \mathrm{mg}$. dissolved in $1 \mathrm{ml}$. of absolute alcohol. was diluted to $10 \mathrm{ml}$. with water in a test tube and $0.5 \mathrm{ml}$. of concentrated sulphuric acid added. The tube was placed in a boiling water bath for half an hour and the formaldehyde liberated with periodic acid determined as described below.

This experiment was repeated, but the sulphuric acid was replaced by $3 \mathrm{ml}$. of $\mathrm{N}$ sodium hydroxide.

The results are shown in Table II.

The ability of deoxycorticosterone to produce the theoretical amount of formaldehyde when allowed to react with periodic acid is unimpaired after treatment with hot dilute mineral acid. The effect of such treatment on cortisone is to reduce the formaldehyde produced to almost negligible proportions.

The effect of hot alkali on deoxycorticosterone was to reduce slightly the amount of formaldehyde produced with periodic acid. After such treatment no formaldehyde whatever could be obtained from cortisone.

It may be suggested that the following conclusions can be made : (1) the side chain $-\mathrm{C}-\mathrm{CO}-\mathrm{CH}: \mathrm{OH}$, such as found in corticosterone and deoxycorticosterone. 
TABLE II

EFFECT OF PREVIOUS ACID OR ALKALINE HYDROLYSIS LIBERATION OF FORMALDEHYDE FROM DEOXYCORTICOSTERONE AND CORTISONE ACETATES WITH PERIODIC ACID

Deoxycorticosterone Acetate

Quantity of deoxycorticosterone acetate used . Theoretical amount of formaldehyde liberated with periodic acid

$1 \mathrm{mg}$.

$81 \mu \mathrm{g}$.

\begin{tabular}{c|c|c}
\hline Reaction No. & Formaldehyde $(\mu \mathrm{g})$. & $\%$ Theoretical \\
\cline { 1 - 3 } 1 & After previous acid hydrolysis \\
2 & 81 & 100 \\
3 & 80 & 99 \\
4 & 80 & 99 \\
& 79 & 97 \\
1 & After previous alkaline hydrolysis \\
2 & 71 & 88 \\
3 & 72 & 89
\end{tabular}

\section{Cortisone Acetate}

Quantity of cortisone acetate used

Theoretical amount of formaldehyde liberated with periodic acid

\begin{tabular}{|c|c|c|}
\hline Reaction No. & Formaldehyde ( $\mu \mathrm{g}$.) & $\%$ Theoretical \\
\hline $\begin{array}{l}1 \\
2 \\
3 \\
4\end{array}$ & $\begin{array}{c}\text { After previous acid hy } \\
9 \\
11 \\
12 \\
10\end{array}$ & $\begin{array}{l}12 \\
15 \\
16 \\
13\end{array}$ \\
\hline $\begin{array}{l}1 \\
2 \\
3\end{array}$ & $\begin{array}{c}\text { After previous alkaline } \\
0 \\
0 \\
0\end{array}$ & $\begin{array}{l}0 \\
0 \\
9\end{array}$ \\
\hline
\end{tabular}

is stable to the action of hot dilute mineral acids. Steroid metabolites with the reduced form of this side chain, - $\mathrm{CH}-\mathrm{CHOH}-\mathrm{CH}_{2} \mathrm{OH}$, could possibly be

encountered, and it is considered that this also might be stable. Corticosterone was found to react similarly to deoxycorticosterone in recovery experiments

from urine. (2) The side chain $-\mathrm{C}-\mathrm{CO}-\mathrm{CH}_{2} \mathrm{OH}$ attached to carbon atom No. 17, such as is found in cortisone, loses its ability to produce formaldehyde with periodic acid after previous treatment with hot dilute mineral acids.

\section{Determination of Corticosterone-like Substances in Urine}

In view of the results obtained in the previous section the following technique has been evolved for the determination of acid-stable corticosteroid-like material in urine. For such substances the term corticosterone-like substances has been coined.

Reagents.-The following are required:

Periodic Acid Reagent.-Potassium periodate, $0.01 \mathrm{M}$, in $0.15 \mathrm{M}$ sulphuric acid.

Chromotropic Acid Reagent.-This is prepared freshly. Specially purified chromotropic acid (Hopkins and Williams, Ltd.), $0.2 \mathrm{~g}$. is dissolved in $2 \mathrm{ml}$. of water and $48 \mathrm{ml}$. of $13 \mathrm{M}$ sulphuric acid added.
Standard Solution of Deoxycorticosterone Acetate (1 $\mathrm{mg} . / \mathrm{ml}$.) in Absolute Alcohol.-This steroid was used as the standard, since it is readily available. It may be obtained from Messrs. Organon, Ltd.

Hydrolysis and Extraction.-Urine, $100 \mathrm{ml}$., and $20 \mathrm{ml}$. of concentrated hydrochloric acid are heated to boiling under a reflux condenser and the boiling continued for 10 minutes.

The mixture is extracted three times with $50 \mathrm{ml}$. quantities of chloroform. The combined chloroform extracts are washed once with $50 \mathrm{ml}$. of $\mathrm{N}$ sodium hydroxide and twice with $50 \mathrm{ml}$. quantities of water. The chloroform extract is dehydrated with anhydrous sodium sulphate, and then evaporated to dryness in an all-glass still.

Treatment with Periodic Acid.-The dry residue of the above chloroform extract is dissolved in $1 \mathrm{ml}$. of absolute alcohol. This solution is transferred quantitatively to a $50-\mathrm{ml}$. flask attached to a watercooled condenser, together with water to a total volume of $10 \mathrm{ml}$. Periodic acid reagent, $5 \mathrm{ml}$., concentrated sulphuric acid, $0.5 \mathrm{ml}$., and a glass bead are added. The mixture is heated to boiling and the distillate collected in a conical tube (graduated at $10 \mathrm{ml}$.) containing $1 \mathrm{ml}$. of $1 \% \mathrm{w} / \mathrm{v}$ sodium sulphite solution. Distillation is continued until a total volume of $10 \mathrm{ml}$. is obtained.

A complete blank is carried out at the same time.

Colorimetric Determination of Formaldehyde.-Into a test tube are measured $1 \mathrm{ml}$. of distillate, $2 \mathrm{ml}$. of water, and $5 \mathrm{ml}$. of chromotropic acid reagent. The contents are well mixed. A blank is set up at the same time in which $1 \mathrm{ml}$. of "blank" distillate is used. The tubes are placed in a boiling water bath for 30 minutes, then cooled and diluted to $10 \mathrm{ml}$. with $9 \mathrm{M}$ sulphuric acid.

Absorptions were read in a "unicam" spectrophotometer G.P. 350 at $565 \mathrm{~m}^{\prime \prime}$. The instrument was set with the blank.

Readings were calculated in terms of deoxycorticosterone from a curve prepared from a standard solution of the acetate.

Deoxycorticosterone Standard Curve. - The standard curve was prepared by submitting $0.5,1.0 .1 .5$, and $2.0 \mathrm{mg}$. of deoxycorticosterone acetate $(0.5,1.0$, 1.5 , and $2.0 \mathrm{ml}$. of the standard solution) to the above procedure. hydrolysis and extraction being omitted.

Recovery Experiments.--The following recovery experiments have been carried out : (1) known quantities of deoxycorticosterone acetate $(0.5$ and $1.0 \mathrm{mg}$.) were added to $100 \mathrm{ml}$. of urine, (2) known quantities of corticosterone $(0.5$ and $1.0 \mathrm{mg}$.) were added to $100 \mathrm{ml}$. of urine, and (3) $1 \mathrm{mg}$. quantities of cortisone acetate were added to $100 \mathrm{ml}$. of urine.

The recovery of deoxycorticosterone was $\mathbf{9 0 - 9 8 \%}$ and of corticosterone was $84-90 \%$. The recovery of cortisone was negligible.

Excretion of Corticosterone-like Substances in Urine.-The determination of corticosterone-like substances has been carried out in human urine in the 
following conditions: (1) normal (Table III), (2) hypoand hyper-adrenalism (Table III), (3) before. during. and after the administration of A.C.T.H. (a typical case is illustrated in Fig. 1), (4) before, during, and after the administration of deoxycorticosterone acetate (Fig. 2), (5) after the intravenous administration of deoxycorticosterone glucoside (Fig 3), and (6) before and during the administration of cortisone acetate.

TABLE III

CORTICOSTERONE-LIKE SUBSTANCES IN URINE

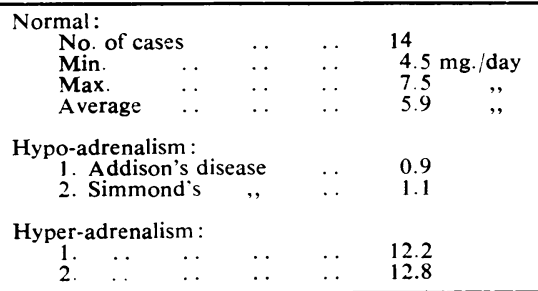

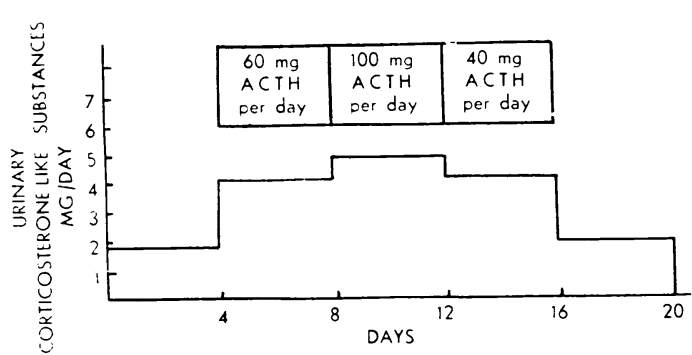

FIG. 1. The excretion of corticosterone-like substances before. during, and after the administration of A.C.T.H. in a case of hypopituitarism

$10 \mathrm{mg}$ DOCA/DAY
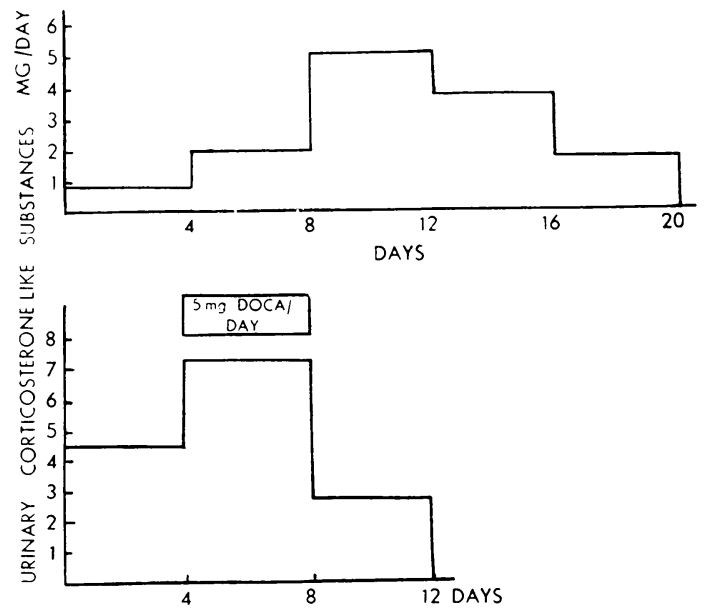

FiG. 2.-The excretion of corticosterone-like substances before, during, and after the administration of deoxycorticosterone acetate in Addison's disease (top figure) and in normals (lower figure).

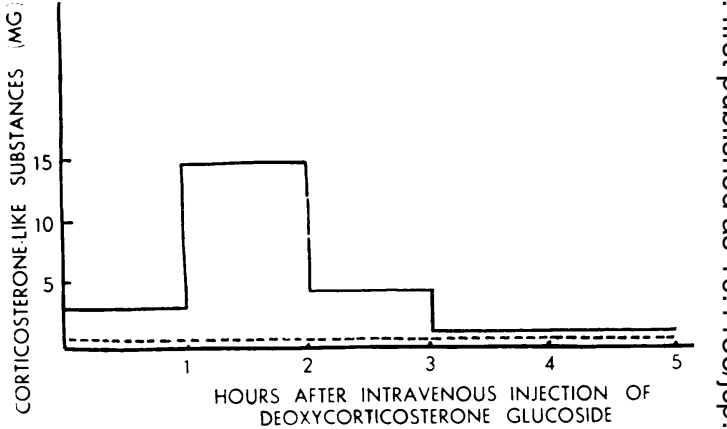

Fig. 3.-The excretion of corticosterone-like substances after the intravenous injection of deoxycorticosterone glucoside. The. dotted line indicates the average excretion under normal condition

Deoxvcorticosterone equivalent administered .. $32 \mathrm{mg}$.

Deoxvcorticosterone equivalent recovered in the

$\begin{array}{lllll}\text { urine during } 5 \text { hours } & . & . & . & 21.2 \mathrm{mg}\end{array}$

Normal urine has been found to contain $4.5-7.5 \mathrm{mg}$. per diem of corticosterone-like substances. Low values were found in hypo-adrenalism and increased values in hyper-adrenalism. Values were increased $\overrightarrow{0}$ during the administration of A.C.T.H., deoxycorti- $\omega$ costerone acetate, and glucoside. The administration of cortisone acetate produced no immediate effect.

\section{Discussion}

The adrenal cortical steroids are probably sub-㐫 jected to a variety of degradation reactions. It $\underset{\vec{F}}{\vec{F}}$ will only be possible to assign the origin of those을 metabolic products which possess a characteristic in chemical structure similar to that of the adrenalo steroids. Steroids possessing the characteristic side chain, - $\mathrm{CO} . \mathrm{CH}_{2} \mathrm{OH}$, or its reduced form,? $-\mathrm{CHOH} . \mathrm{CH}_{2} \mathrm{OH}$, can be regarded as having someo definite relation to the biologically active steroids

There are two general types of method availableo for the chemical determination of these metabo- 2 lites : (1) reduction methods, and (2) the measure-음 ment of the formaldehyde liberated when the steroid is allowed to react with periodic acid. The former will include other steroids to a certain extent, but will not include those containingo the $-\mathrm{CHOH} . \mathrm{CH}_{2} \mathrm{OH}$ grouping. The periodic acid 0 method will include only those steroids containing the $-\mathrm{CO} . \mathrm{CH}_{2} \mathrm{OH}$ or $-\mathrm{CHOH} . \mathrm{CH}_{2} \mathrm{OH}$ groupings. F

Bio-assay methods always tend to give mucho lower results than chemical methods. The latter undoubtedly include biologically inactive metabo $\stackrel{0}{\rightarrow}$ lites, and if the aim is to measure the total outputo of the adrenal gland, then these should be included

The greatest problem in corticoid determination

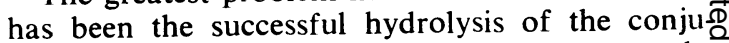
gates which undoubtedly predominate over theo free steroids. Previously published chemica 
methods estimate only the free steroids, and in some cases a very small part of the conjugated steroids. In the present investigation it has been shown that the side chain that is typical of corticosterone and deoxycorticosterone is stable to the action of hot dilute mineral acid. This side chain is the source of the formaldehyde released on reaction of the steroids with periodic acid. For this reason, the standard hydrolytic procedure used in the determination of the 17-ketosteroids has been utilized as a preliminary to the determination of this group. It is almost certain, especially in the case of corticosterone, that some structural changes do occur as the result of this treatment resulting in the loss of biological activity. Substances such as cortisone, with a hydroxyl group attached to the seventeenth carbon atom, are so affected by hot dilute mineral acids as not to be determined.

Normal human urine appears to contain quite large amounts of steroid-like substances related to corticosterone. Recent publications (Pincus, Hechter, and Zaffaroni, 1951 ; Bush, 1952) have shown that 17-hydroxycorticosterone and corticosterone are major constituents of adrenal cortical secretions and that deoxycorticosterone is present but in smaller quantities.

The application of the present technique has produced some interesting results, but a complete picture of adrenal cortical activity cannot be obtained until methods are available for the determination of the 17-hydroxycorticoids. Work on this subject is now in progress.

\section{Summary}

When the acetates of deoxycorticosterone and cortisone are distilled with dilute sulphuric and periodic acids in aqueous solution, the theoretical amount of formaldehyde is obtained as determined colorimetrically with chromotropic acid.

The above reaction is unimpaired if deoxycorticosterone has been subjected to previous treatment with hot dilute mineral acids. Cortisone acetate produces but negligible amounts of formaldehyde with periodic acid if it had previously been treated with hot dilute mineral acids.

A method is described for the determination of the acid stable corticosteroids (corticosterone-like substances) in urine. This involves hydrolysis of the conjugates with hot dilute mineral acid. The steroid extract was subjected to a modified periodic acid technique and the formaldehyde liberated determined colorimetrically with chromotropic acid. Deoxycorticosterone and corticosterone added to urine could be recovered quantitatively. Cortisone added to urine could not be recovered.

Normal urine was found to contain 4.5 to $7.5 \mathrm{mg}$. per diem of corticosterone-like substances.

Low values were observed in hypo-adrenalism and elevated values in hyper-adrenalism.

Increased values followed the administration of deoxycorticosterone and A.C.T.H. No immediate effect followed the administration of cortisone.

I should like to thank Professor T. Reichstein for a gift of corticosterone.

\section{REFERENCES}

Bush, I. E. (1952). Biochem. J., 50, 370.

Daughaday, W. H., Jaffe, H., and Williams, R. H. (1948). J. clin. Endocr., 8, 166.

Pincus, G., Hechter, O., and Zaffaroni, A. (1951). Proceedings of the 2nd Clinical ACTH Conference, ed. Mote, J. R., vol. 1, p. 40, London. 